\title{
The influence of soil steaming on some properties of the soil and on the growth and heading of winter glasshouse lettuce. III. The influence of nitrogen form, manganese level and shading studied in sand culture experiments with trickle irrigation ${ }^{1}$
}

\author{
G. Jager, J. van der Boon and G. J. G. Rauw \\ Institute for Soil Fertility, Haren-Groningen, the Netherlands \\ Received: 30 January 1970
}

\section{Summary}

A study was made of the influence of ammonium and manganese on heading of winter lettuce. Both factors can be present in excess after steaming of the soil. Conditions of restricted light were included in the experiments.

Lettuce was grown in plastic pots with sand, trickle irrigated with nutrient solutions, which differed in nitrogen form and manganese content. Part of the plants was grown under the prevailing light conditions in autumn, winter and spring, the others were shaded, which reduced light intensity with 25 to $50 \%$.

Insufficient light conditions as well as ammonium-excess as manganese accumulations stimulated poor heading (Fig. 1, Fig. 2). Poor heading was attended with a low mass production. The same factors affected the length/breadth ratio of the leaves in a similar way.

There were a few indications that the combined effects of the factors studied were extra dangerous for heading of lettuce, except that manganese in the plant tended to be more increased by supplying nitrogen in the form of ammonium than in the form of nitrate. In the case of a better prospering plant with nitrate supply, however, Mn accumulation was more detrimental.

Heading of winter lettuce is endangered by poor light conditions and by ammonium and manganese accumulation as consequence of the steaming of the soil. Soil steaming can be better postponed to the spring, after the winter lettuce, or should be carried out carefully under certain conditions or with counter-measures.

\section{Introduction}

Heading of winter glasshouse lettuce on steamed soil can be poor. A more or less hollow and relatively long head is formed, which is generally only loosely or not at all closed on its top (called a 'tulip', Fig. 1). In our first paper (Jager et al., 1969a)

1 More information is given in: G. Jager, J. van der Boon and G. J. G. Rauw, Heading of winter lettuce on steamed soil: influence of nitrogen form, manganese level and shading. Rapp. Inst. Bodemvruchtbaarheid, Haren-Groningen, No 6 (1970). 


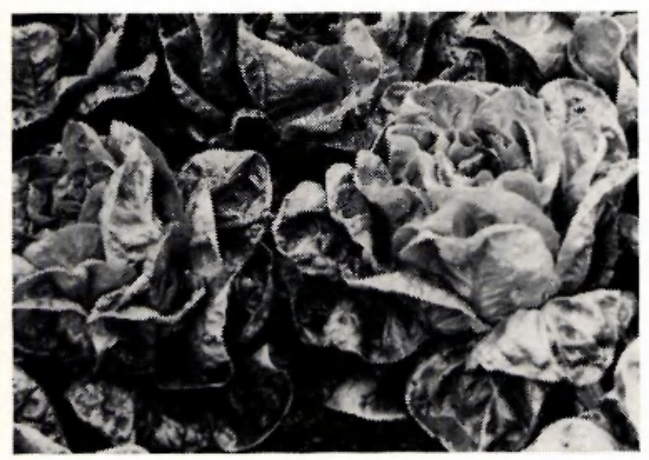

Fig. 1 Poor heading of lettuce on steamed soil in practice (photo Dr L. S. Spithost)

the changes in the soil properties due to steaming were discussed. In a second paper (Jager et al., 1969 b) the growth of lettuce on steamed and unsteamed soil, its heading and chemical composition were compared and discussed. In this paper the separate and combined effects of ammonium and manganese accumulations on the heading of lettuce in sand culture is presented, whether or not combined with a reduced light intensity. In steamed soils accumulations of $\mathrm{Mn}$ and $\mathrm{NH}_{4}$ ions occur and they may be the cause of the malformation, especially when the light conditions during autumn and early winter are unfavourable.

\section{Lay-out of the experiments}

Five experiments were carried out with the lettuce variety 'Proeftuin's Blackpool', three in the period from October 1963 to April 1964 and two in the period from October 1964 to March 1965. The first experiment included the combination of three factors at two levels: two nitrogen levels, two kinds of nitrogen, viz $\mathrm{NO}_{3}-\mathrm{N}$ and $\mathrm{NH}_{4}-\mathrm{N}$ and two light intensities, viz the prevailing light intensity and one reduced by shading with muslin from 10 a.m. to 4 p.m. or to 2 p.m. under bright or dark weather conditions, respectively. In the following experiments the two levels of nitrogen were reduced to one, but two levels of manganese were included now: a sufficient Mn level of $1.2 \mathrm{ppm}$ and a slightly toxic level, varying from 11.7 to $25 \mathrm{ppm}$ in the different experiments in search of the right borderline case.

Nitrification of $\mathrm{NH}_{4}-\mathrm{N}$ occurred already after a few days and proceeded at a high rate. Therefore the first experiments may not be wholly representative, although there has been an excessive ammonium supply every day. In the last two experiments $1 \mathrm{ppm}$ $\mathrm{N}$-serve (2-chloro-6-(trichloromethyl) pyridine) was supplied to both $\mathrm{NH}_{4}$ and $\mathrm{NO}_{3}$ nutrient solutions (Goring, 1962). The nitrification proved completely prevented now. The growth of the lettuce plants, however, seemed somewhat irregular yet in spite of the low level of $\mathrm{N}$-serve.

The lettuce was grown in plastic 4-liter pots, filled with moderately fine sand. The nutrient solution was trickled one to three times a day, depending on the need. $\mathrm{CO}_{2}$ was supplied during the experiments and thus could not be a limiting factor in photosynthesis.

The experiment was laid out as splitplot in four replications, and with five pots per plot. 


\section{Results}

\section{Light conditions}

The light intensity was reduced with 25 to $50 \%$ by means of shading with muslin. During the experiment, the light intensity, however, was not constant, decreasing during the experimental period in autumn just as in practice, but increasing in spring. Thus the improving light conditions during the experiment VP 692, in which the plants grew from 19/3/1964 until 29/4/1964, prevented the appearance of poor heading in spite of shading. In the other four experiments shading appeared to be an important factor for promoting 'tulip' formation, indicating that poor light conditions in the autumn, especially in unfavourably built glasshouses, are a main factor for the appearance of the malformation. Shortage of light also gave a significant decrease of the dry weight of the plant.

\section{$\mathrm{NH}_{4}$ accumulation}

After steaming $\mathrm{NH}_{4}-\mathrm{N}$ accumulates in the soil. The amount of nitrate in the soil is reduced or has altogether disappeared. Ammonium supply stimulated here the appearance of bad heading. Nitrate gave a firmer, more flat, less dark green plant. The production of dry matter was higher when nitrate than ammonium-nitrogen was supplied (Table 1, Fig. 2). In three of four experiments poor heading by ammonium was more pronounced under shading than under prevailing light and in all five experiments the difference in production in favour of nitrate was more distinct under poor light conditions. Per experiment these interactions, however, were not statistically significant.

\section{Mn accumulation}

In preliminary sand and water culture experiments it was tried to evoke the poor heading of the lettuce. From these experiments it was found that 'tulip' formation may be seen as a borderline case of manganese excess. High doses of manganese markedly reduced the growth of the plant and the latter showed symptoms of manganese excess in the leaves: in the oldest leaves fine brown necrotic spots over the whole leaf, later on yellowing and dying of the leaf margins, proceeding from the outside inwards. The fine necrotic dotting of the leaves was found after steaming,

Table 1 The effect of the form of nitrogen on heading and dry weight of lettuce

\begin{tabular}{|c|c|c|c|c|}
\hline \multirow{2}{*}{$\begin{array}{l}\text { Experiment } \\
\text { No }\end{array}$} & \multicolumn{2}{|c|}{ Difference between $\mathrm{NH}_{4}$ and $\mathrm{NO}_{3}$} & \multicolumn{2}{|c|}{ Statistical evaluation $^{3}$} \\
\hline & heading ${ }^{1}$ & $\begin{array}{c}d r y \text { weight }{ }^{2} \\
(g / \text { plant })\end{array}$ & heading & $d r y$ weight \\
\hline VP 597 & +0.2 & -0.3 & n.s. & n.s. \\
\hline VP 674 & +1.2 & -0.3 & $+t$ & n.s. \\
\hline VP 692 & - & -0.5 & - & +++ \\
\hline VP 737 & +0.5 & -0.2 & n.s. & n.s. \\
\hline VP 758 & +0.6 & -1.1 & + & +++ \\
\hline
\end{tabular}

Scale $0-10: 0=$ good head $; 10=$ poor head.

2 Dry weight: averages of experiments diverging from 4.5 to $8.5 \mathrm{~g} / \mathrm{plant}$.

$3(+)=\mathrm{P}<0.10 ;+=\mathrm{P}<0.05 ;++=\mathrm{P}<0.01 ;+++=\mathrm{P}<0.001 ;$ n.s. $=$ not significant. 

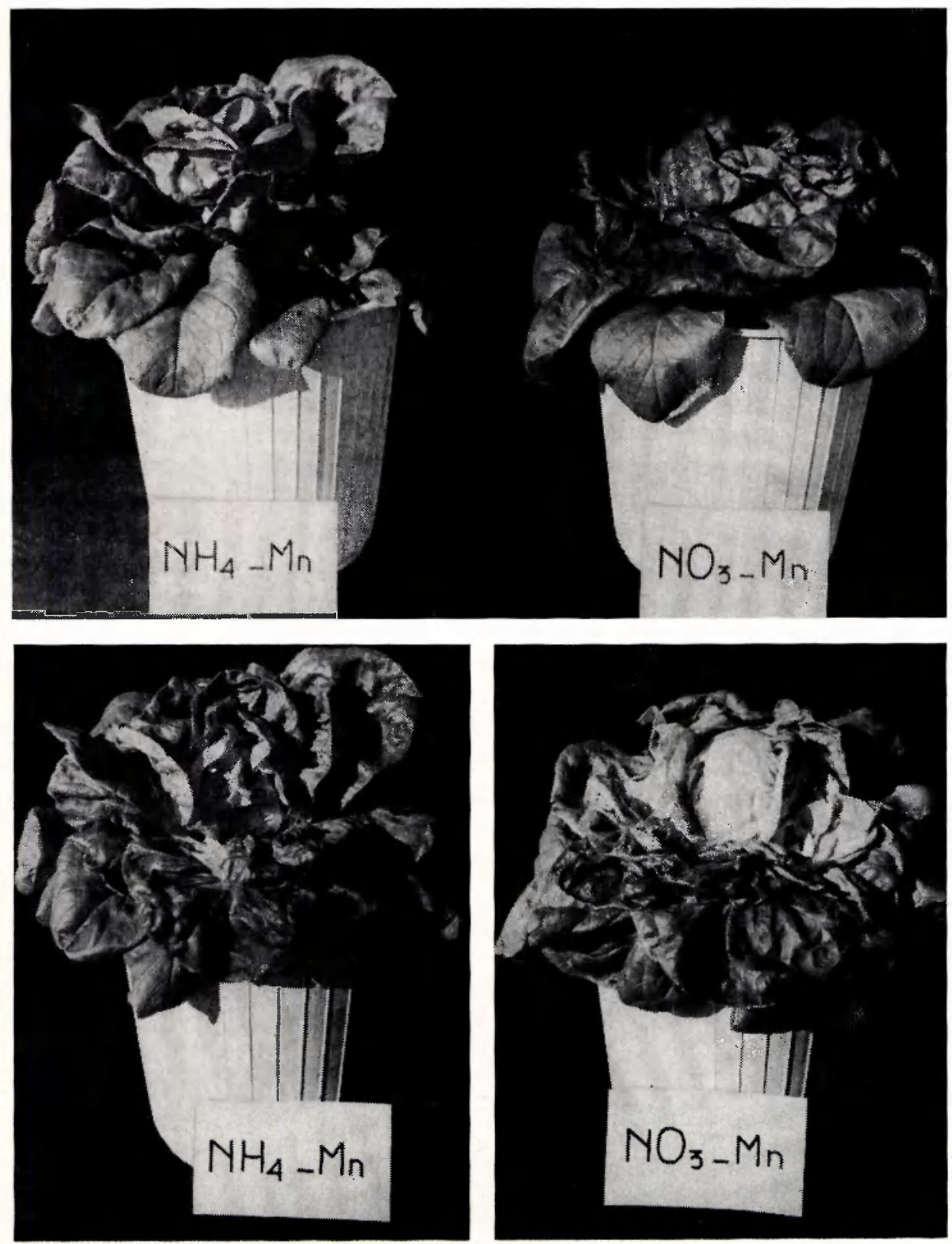

Fig. 2 Influence of $\mathrm{NH}_{4}-\mathrm{N}$ and $\mathrm{NO}_{3}-\mathrm{N}$ on habitus of lettuce in pot experiment (intact and exposed plants) 


\section{G. JAGER, J. VAN DER BOON AND G. J. G. RAUW}
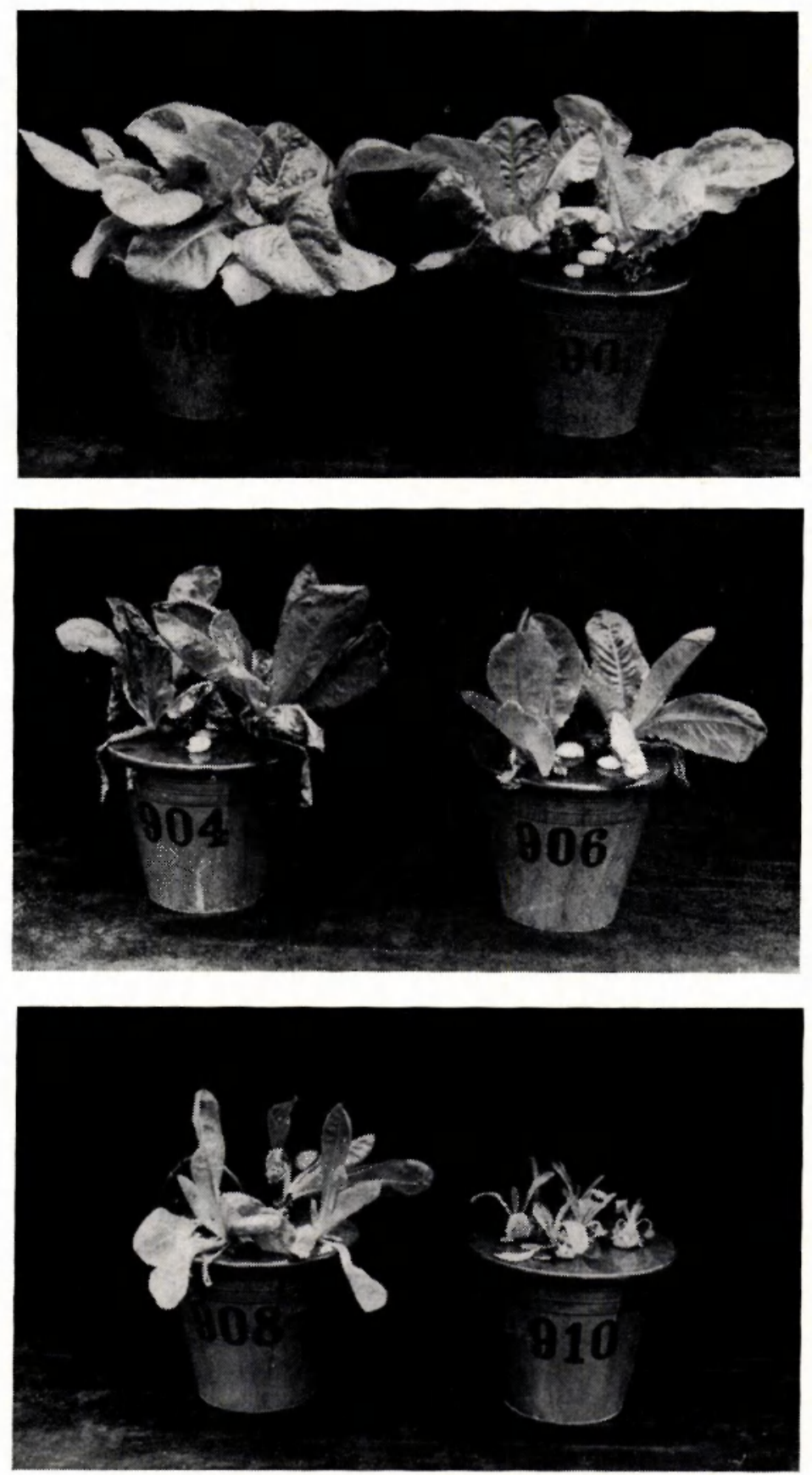

Fig. 3 Influence of Mn excess on lettuce, variety 'Blackpool', in water culture (Nos 900-902 - 904 906-908-910:0.37-9.25-18.5-37-74-111 ppm) 
INFLUENCE OF SOIL STEAMING ON SOME PROPERTIES OF THE SOIL . . III

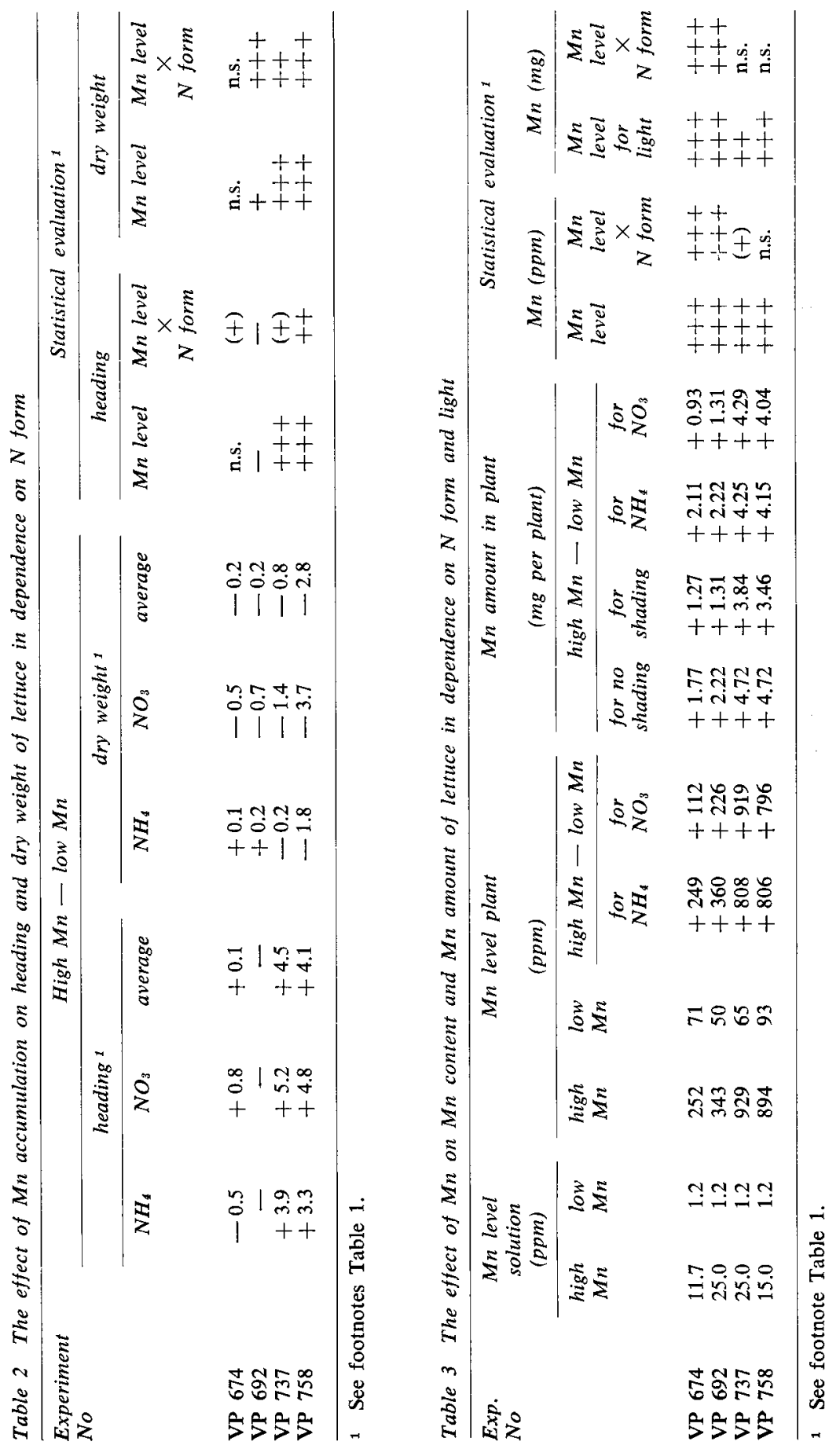

Neth. J. agric. Sci. 18 (1970) 
especially on sandy soils with low $\mathrm{pH}$. At low levels of Mn poisoning, viz $9.3 \mathrm{ppm} \mathrm{Mn}$, the leaves were more spoonshaped and more erected, giving a resemblance to some features of the malformation after steaming (see Fig. 3).

A high Mn level, chosen so, that no serious growth reduction occurred, appeared to have indeed an unfavourable influence on heading of lettuce (Table 2). The stimulation of poor heading by manganese was for the ammonium plants, which already showed a less good heading, less pronounced than for plants supplied with nitrate. The harmful effect of a high manganese dose upon the dry weight production also appeared more clearly with the better prospering plants on nitrate.

The $\mathrm{Mn}$ content of the plant increased when a high $\mathrm{Mn}$ dose was given. In two of four experiments this occurred significantly more for the $\mathrm{NH}_{4}$ plants than for the $\mathrm{NO}_{3}$ plants (Table 3). Here thus the first sign of an unfavourable interaction between manganese accumulation and $\mathrm{N}$ form, in contrast with the effect on heading and production of dry weight. The total $\mathrm{Mn}$ amount in the plant was also increased more, when $\mathrm{NH}_{4}$ was given.

The manganese content of the leaf was not clearly influenced by shading, the total Mn amount per plant was decreased due to the growth reduction. The increase of the manganese amount in the head at the high Mn level was significantly larger when shading was not carried out. Growth reduction from shading thus was not accompanied by an undesired increase of manganese in the plant, so the unfavourable effect of steaming presumably cannot be ascribed to an uncontrolled $\mathrm{Mn}$ absorption under less favourably light conditions.

\section{Morphogenetic study of the leaf}

For a better evaluation of the effect of the factors studied on the ability of the plant for good heading, the length and breadth of the leaves were measured. In case of a constant, good light intensity the length/breadth ratio $(1 / b)$ of the leaves, ranged from old to young, reaches a stationary low level (Bensink, 1958, 1962). A decrease in light intensity is attended with an increase in the $1 / b$ ratio of the leaves.

The measurements confirmed the influences on heading already mentioned. Shading and high manganese levels caused an increase of the $1 / b$ ratio. Generally nitrate favoured the breadth growth of the leaf. Table 4 briefly represents the effects by means of the lowest found $1 / b$ ratio. Fig. 4 gives an idea of the variation of the $1 / b$

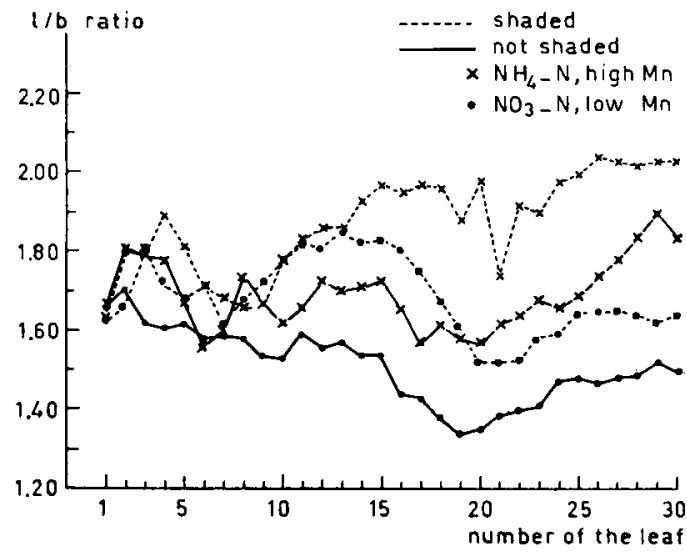

Fig. 4 Length/breadth ratios of leaves, arranged from base to top, as influenced by light, $N$-form and $\mathrm{Mn}$. Contrast is given of: $\mathrm{NO}_{3}+$ low $\mathrm{Mn} ; \mathrm{NH}_{4}+$ high $\mathrm{Mn}$ under light and shade conditions 
INFLUENCE OF SOIL STEAMING ON SOME PROPERTIES OF THE SOIL . . III

Table 4 Influence of light, $N$ form, and $M n$ level on the lowest length/breadth ratio of lettuce leaf

\begin{tabular}{|c|c|c|c|c|c|c|c|c|}
\hline \multirow{3}{*}{$\begin{array}{l}\text { Exp. } \\
\text { No }\end{array}$} & \multicolumn{4}{|c|}{ Not shaded } & \multicolumn{4}{|c|}{ Shaded } \\
\hline & \multicolumn{2}{|c|}{ low $M n$} & \multicolumn{2}{|c|}{ high $M n$} & \multicolumn{2}{|c|}{ low $M n$} & \multicolumn{2}{|c|}{ high $M n$} \\
\hline & $\mathrm{NH}_{4}$ & $\mathrm{NO}_{3}$ & $\mathrm{NH}_{4}$ & $\mathrm{NO}_{3}$ & $\mathrm{NH}_{4}$ & $\mathrm{NO}_{3}$ & $\mathrm{NH}_{4}$ & $\mathrm{NO}_{3}$ \\
\hline VP 674 & 1.06 & 0.99 & 1.02 & 1.00 & 1.17 & 1.15 & 1.22 & 1.16 \\
\hline VP 692 & 1.23 & 1.15 & 1.28 & 1.24 & 1.44 & 1.40 & 1.47 & 1.35 \\
\hline VP 737 & 1.43 & 1.34 & 1.56 & 1.57 & 1.63 & 1.52 & 1.66 & 1.66 \\
\hline VP 758 & 1.11 & 1.04 & 1.38 & 1.24 & 1.22 & 1.14 & 1.59 & 1.44 \\
\hline
\end{tabular}

ratio under influence of the factors. In this experiment, performed in the late autumn under less favourable light conditions, a high $\mathrm{Mn}$ dosis did not give a constant $\mathrm{l} / \mathrm{b}$ ratio, but a gradually increasing one.

\section{Discussion}

The three factors: shortage of light and excess of $\mathrm{NH}_{4}$ and $\mathrm{Mn}$ appeared all to have an unfavourable influence on heading of lettuce.

For lettuce we know from the work of Bensink (1958) and Dulforce (1963) that light intensity and day length should not be below certain temperature-dependent limits for a good head to be formed. When conditions for photosynthesis are unfavourable such as low light intensity, short days, too low a $\mathrm{CO}_{2}$ concentration or a partial elimination of the outer leaves, the $1 / b$ ratio of the leaves is higher. Plants with too high a $1 / b$ ratio do not form a head (Bensink, 1958).

As regards the $\mathrm{N}$-form lettuce belongs to the large group of ammonium-sensitive plants (Davidson and Thiegs, 1966). High concentrations of ammonium adversely affect the crop (Grogan and Zink, 1956). The $\mathrm{NH}_{4}$ ion competes with other cations during uptake and promotes the uptake of anions, while it itself is lost in the plant by assimilation, thus giving easily too low a C-A value (de Wit et al., 1963). Lettuce can probably withstand this unsufficiently.

Under sub-optimal light conditions the need for light is higher for plants grown with ammonium. $\mathrm{NH}_{4}-\mathrm{N}$ in the plant is converted rapidly and in an uncontrolled way into organic nitrogen compounds and tends to deplete the available carbohydrates, especially if the light conditions are marginal (Nightingale, 1948; Ferguson, 1957; Barker et al., 1965). The difference in shape and upright position of the leaves may also contribute to a lower photosynthesis of the $\mathrm{NH}_{4}$-plants, due to reduction of active leaf area by overlap. Brouwer and Huyskes (1968) compared the growth of two lettuce varieties and found that the variety showing the greatest overlap made the slowest growth. These facts make it probable that poor heading by ammonium is more pronounced at poor light conditions.

Lettuce is moderately susceptible of manganese excess (Hewitt, 1948; Löhnis, 1951; Williams and Vlamis, 1957). The common characteristic is a pale foliage with a dull yellow around the leaf margin (Sherman and Fujimoto, 1946; Hewitt, 1948) or marginal paling (Heslep, 1951; Vlamis, 1953) and in a later stage browning and darkening of the veins (Löhnis, 1951; Sonneveld, 1967) and necrosis of the leaf disc. The unfavourable effect of $\mathrm{Mn}$ accumulation on the heading looks to be not a direct toxicity 
symptom, but may be ascribed to its contribution to an increased $1 / b$ ratio of the leaves, so endangering a good head formation.

In general, the harmful effect of manganese excess is less pronounced under restricted light conditions. The Mn content is also decreased (McCool, 1935; Löhnis, 1951; Dey, 1964). This does, however, not agree with the results of the experiments of Sonneveld (1965): in winter conditions the lettuce showed symptoms of $\mathrm{Mn}$ toxicity, but the following crop in spring was apparently sound. The range of manganese contents of 252-929 ppm in our experiments means a level for mild toxicity symptoms (Messing, 1965; Heslep, 1951; Löhnis, 1951). Manganese stimulated poor heading in three of four experiments, but did not in one with fast-growing lettuce under good light conditions. Within the experiments no interaction between $\mathrm{Mn}$ accumulation and light conditions occurred.

Löhnis (1951) found an increased toleration for $\mathrm{Mn}$ by high temperature. If true the slow decrease of temperature in autumn might make the lettuce more susceptible for Mn excess.

The influence of the nitrogen source on the appearance of manganese toxicity is not clear from literature. In culture solutions the nitrate stimulates the toxicity of $\mathrm{Mn}$ (Mulder and Gerretsen, 1952; Millikan, 1950). Dey (1964), however, could not confirm this. In our experiments the manganese excess decreased the dry matter production with nitrate stronger than with ammonium, absolutely and relatively.

For the growth of well-headed winter lettuce it is better to postpone the steaming to the spring before tomato growing. If not possible, the soil should be steamed in a relatively dry condition, restricting the temperature and duration of the treatment to a minimum, to avoid excessive formation of ammonium, available manganese and other solubilized substances. Leaching of soluble inorganic and inhibitory organic materials, although of benefit, has the drawback to enhance the amount of available $\mathrm{Mn}$ (van der Hoeven, 1967). Reinfection of the sterilized soil with saprophytic microorganisms together with the addition of a moderately decomposable nitrogen-poor substratum, for instance straw chaff (Hartmann, 1961; Wiebe, 1968), brought into the soil soon after steaming, will lead to immobilization of $\mathrm{NH}_{4}-\mathrm{N}$ by the developing microflora, will reduce the amounts of available $\mathrm{Mn}$ sooner by biological oxidation, will stimulate the decomposition of inhibiting organic compounds and will lead to a sooner start of the nitrification. Nitrogen fertilization, if necessary, should be given as nitrate (Wiebe, 1968). The release of $\mathrm{Mn}$ during steaming is restricted when the soil has a neutral $\mathrm{pH}$; liming of a too acid soil before steaming, however, stimulates $\mathrm{NH}_{4}$ accumulation.

Factors governing photosynthesis should be kept as best as possible: light and $\mathrm{CO}_{2}$ supply.

In future the method of soil pasteurization with a steam-air mixture may be a way out.

\section{References}

Barker, A. V., R. J. Volk \& W. A. Jackson, 1965. Effects of ammonium and nitrate nutrition on dark respiration of excised bean leaves. Crop Sci. 5: 439-444.

Bensink, J., 1958. Morphogenetic effects of light intensity and night temperature on the growth of lettuce (Lactua sativa L.), with special reference to the process of heading. Proc. K. Ned. Akad. Wet. C 61 : 89-100. 
Bensink, J., 1962. A comparative morphogenetic study of some new winter varieties of lettuce. Proc. 16th int. hort. Congr. (Brussels, 1962) II : 76-80.

Brouwer, R. \& J. A. Huyskes, 1968. A physiological analysis of the responses of the lettuce variety 'Rapide' and its hybride with 'Hamadan' to day-length and light intensity. Euphytica 17: 245-251.

Davidson, J. H. \& B. J. Thiegs, 1966. The effect of soil fumigation on nitrogen nutrition and crop response. Down to Earth 22: 7-12.

Dey, S., 1964. Report of work done at the Institute of Soil Fertility, Groningen, during the period February 1963-June 1964. Instituut voor Bodemvruchtbaarheid, Groningen, pp. 164.

Dullforce, W. M., 1963. Analysis of the growth of winter glasshouse lettuce varieties. Rep. Sch. Agric. Univ. Nott. 1962: 57-64.

Ferguson, J., 1957. Beneficial soil micro-organisms. In: K. F. Baker, The U.C. system for producing healthy container-grown plants. Manual Calif. agric. Exp. Stn 23: 248-254.

Goring, C. A. J., 1962. Control of nitrification of ammonium fertilizers and urea by 2-chloro-6(trichloromethyl) pyridine. Soil Sci. 93: 431-439.

Grogan, R. G. \& F. W. Zink, 1956. Fertilizer injury and its relationship to several previously described diseases of lettuce. Phytopathology 46: 416-422.

Hartmann, H. D., 1961. Beobachtungen bei Gewächshausböden nach dem Dämpfen. Rhein. Mschr. Gemüse-, Obst- u. Gartenb. 49: 368-369.

Heslep, J. M. A., 1951. Study of the infertility of two acid soils. Soil Sci. 72: 67-80.

Hewitt, E. J., 1948. Resolution of the factors in soil acidity. IV. The relative effects of Al and Mn toxicities on some farm and market garden crops. A. Rep. agric. hort. Res. Stn Univ. Bristol 1948: 58-65.

Hoeven, A. P. van der, 1967. De groei van sla na doorspoelen van gestoomde grond. Tuinderij 7: 771-772.

Jager, G., J. van der Boon \& G. J. G. Rauw, 1969a. The influence of soil steaming on some properties of the soil and on the growth and heading of winter glasshouse lettuce. I. Changes in chemical and physical properties. Neth. J. agric. Sci. 17: 143-152.

Jager, G., J. van der Boon \& G. J. G. Rauw, 1969b. The influence of soil steaming on some properties of the soil and on the growth and heading of winter glasshouse lettuce. II. The reaction of the crop. Neth. J. agric. Sci. 17: 241-245.

Löhnis, M. P., 1951. Manganese toxicity in field and market garden crops. Pl. Soil 3: 193-222.

McCool, M. M., 1935. Effect of light intensity on the manganese content of plants. Contr. Boyce Thompson Inst. Pl. Res. 7: 427-437.

Messing, J. H. L., 1965. The effects of lime and superphosphate on manganese toxicity in steamsterilized soil. Pl. Soil 23: 1-16.

Millikan, C. R., 1950. Relation between nitrogen source and the effects on flax of an excess of manganese or molybdenum in the nutrient solution. Aust. J. Sci. Res. Ser. B 3: 450-473.

Mulder, E. G. \& F. C. Gerretsen, 1952. Soil manganese in relation to plant growth. Adv. Agron. 4: $221-277$.

Nightingale, G. T., 1948. The nitrogen nutrition of green plants. II. Bot. Rev. 14: 185-221.

Sherman, G. D. \& C. K. Fujimoto, 1946. The effect of the use of lime, soil fumigants and mulch on the solubility of manganese in Hawaiian soils. Proc. Soil Sci. Soc, Am. 11: 206-210.

Sonneveld, C., 1965. De invloed van mangaan op de ontwikkeling van sla. Proefstation voor de Groenten- en Fruitteelt onder Glas, Naaldwijk, pp. 12.

Sonneveld, C., 1967. Mangaanovermaat bij sla op gestoomde gronden. Tuinderij 7: 852-853.

Vlamis, J., 1953. Acid soil infertility as related to soil-solution and solid phase effects. Soil Sci. $75: 383-394$.

Wiebe, H. J., 1968. Anbau von Kopfsalat nach Bodendämpfung. Gemüse 4: 63-65.

Williams, D. E. \& J. Vlamis, 1957. Manganese and boron toxicities in standard culture solutions. Proc. Soil Sci. Soc. Am. 21: 205-209.

Wit, C. T. de, W. Dijkshoorn \& J. C. Noggle, 1963. Ionic balance and growth of plants. Versl. landbouwk. Onderz. 69.15, pp. 68. 